\title{
BiP peptides induce epitope-specific T-cell reactions in RA
}

New research shows that peptides derived from the rheumatoid arthritis (RA) autoantigen immunoglobulinbinding protein (BiP, also known as 78 $\mathrm{kDa}$ glucose-regulated protein [GRP78]) are differentially recognized by effector and regulatory $\mathrm{T}$ cells, and points to BiP-specific T-cell subsets as potential therapeutic targets in RA.

In the study, peripheral blood mononuclear cells (PBMCs) from patients with RA carrying the HLADRB1 shared epitope were cultured in the presence or absence of peptides derived from

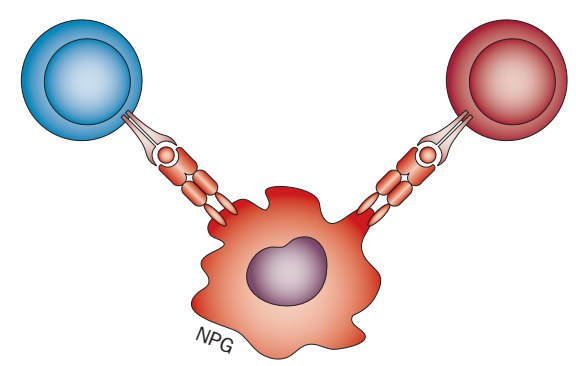

human BiP for 96 h. Among 42 different $\mathrm{BiP}$-derived epitopes screened, $\mathrm{BiP}_{336-355}$ was the strongest inducer of T-cell proliferation, with proliferation higher in cells from patients carrying two copies of the shared epitope than those carrying one copy.

Notably, proliferation of PBMCs in response to $\mathrm{BiP}_{336-355}$ correlated with clinical disease activity and serum titres of antibodies against $\mathrm{BiP}$ and citrullinated $\mathrm{BiP}$ in patients with $\mathrm{RA}$. $\mathrm{BiP}_{336-355}$-induced PBMCs secreted the proinflammatory cytokines IL-17A and IFN- $\gamma$, whereas those from healthy donors did not.

Conversely, the regulatory peptide $\mathrm{BiP}_{456-475}$ induced production of IL-10 by CD25+ PBMCs from patients with RA and healthy donors but did not induce cell proliferation. $\mathrm{BiP}_{456-475}$ also suppressed PBMC proliferation and inflammatory cytokine production induced by $\mathrm{BiP}_{336-355^{\circ}}$. In mice with collagen-induced arthritis, oral administration of $\mathrm{BiP}_{456-475}$ peptide during arthritis onset reduced joint inflammation and proliferation of $\mathrm{CD} 4^{+}$ $\mathrm{T}$ cells, and increased IL-10 secretion and numbers of regulatory $\mathrm{T}$ cells.

"Our antigen-specific approach revealed an impairment in the homeostatic balance between autoantigen-specific effector and regulatory T cells in RA," explains corresponding author Keishi Fujio. "This observation suggests that T-cell response to the effector epitope of $\mathrm{BiP}$ overwhelms pre-existing tolerance associated with the regulatory epitope under some unknown stimulation in RA. Moreover, we showed the possibility that an enforcement of autoantigen-specific tolerance may result in the improvement of arthritis."

\section{Sarah Onuora}

Original article Shoda, H. et al. Autoantigen BiP-derived HLA-DR4 epitopes differentially recognized by effector and regulatory T cells in rheumatoid arthritis. Arthritis Rheumatol. doi:10.1002/art.39054 